\title{
Using Environmental Consulting as a Team Design Project: Role Play to Reality
}

\author{
Prof. Greg J. Evans PhD, P.Eng. \\ Dept of Chemical Engineering \\ University of Toronto \\ greg.evans@utoronto.ca
}

\author{
Maygan McGuire, P.Eng \\ Dept of Chemical Engineering \\ University of Toronto \\ m.mcguire@utoronto.ca
}

\author{
Deborah Tihanyi, Lecturer \\ Engineering Communication Program \\ University of Toronto \\ deborah.tihanyi@utoronto.ca
}

\begin{abstract}
Environmental Chemistry is a core course for all second year Chemical Engineering students with a class size of $\sim 120$ students. The course includes $a$ "Consulting Engineering" integrative project which involves elements of role-play based on topics drawn from current, real-life issues.

Students create their own five-member 'company' that responds through a letter of intent to one of three requests for proposal from 'Wallberg Multicorp', a fictitious company based on the home building for Chemical Engineering. Over the term, students submit an interim proposal, meet with the client, and submit a final proposal. Feedback is provided at various stages. The top three groups present their proposals to the class and a panel of professional environmental consultants.

This project allows iterative learning of technical, communication and team skills, with multiple opportunities for feedback and guidance. Student growth, learning and experience are evaluated through the deliverables, reflections and the course evaluations.
\end{abstract}

\section{Introduction}

CHE 230 'Environmental Chemistry' is a core course offered to students in Chemical Engineering at the University of Toronto. Offered in the spring semester of second year, this course examines chemical phenomena occurring in the environment, focusing on the atmosphere and natural waters. Prior to taking this course students complete a full year design course, a course in economics and several other chemistry courses.

A central element of the Environmental Chemistry course is the 'Consulting Engineering' project. This project was designed to allow for project-based learning in a simulated professional atmosphere. The students complete the project in five-member teams selected by the students themselves. The project requires these teams to propose how they would perform a site assessment so as to determine the extent of chemical contamination in one of three scenarios. The fictitious scenarios draw from real-life events relating to air, water or soil pollution. Each scenario incorporates environmental chemistry principles taught in lecture such as the behaviour and fate of chemicals in the environment. The iterative nature of the project provides numerous feedback and learning opportunities. Each year, the most technically competent and professional group from each scenario is selected to present their final proposal to the class.

This project has been delivered in its current teambased format for five years. It evolved from an individual, or paired, argumentative essay that was part of the course laboratory component. This essay allowed aspects of site assessment, field sampling, and instrumental analysis to be explored during the winter when actual field work was not practical. The teambased format was added in 2005 when the course became core in the Chemical Engineering program and grew in size from $\sim 30$ to $120-150$ students. This article describes the implementation of this integrative project and its impact on students.

\section{Project Description}

This section presents the learning objectives of the project, its structure, and the various feedback points implemented within.

\subsection{Learning Objectives}

The primary objective of this project is to provide the students with hands-on experience that induces an understanding of the consulting engineering process and the role of a consulting engineer. Other learning objectives for the project include the development of four main competencies: teamwork and groupleadership, technical knowledge, technical communication, and navigating ambiguity. 
Through completion of this project, student-groups are expected to develop team-based project coordination skills and to demonstrate cohesive team dynamics. The goal is for students to learn valuable teamwork skills and appreciate the potential outcomes achievable through highly effective teams.

Students should also be able to explain and justify the technical aspects associated with their selected sampling and analysis methods. To this end, students must research, applying critical judgement, in order to identify expected contaminants, their behaviour in the environment, and their effects on human health and the health of the biosphere. Students should account for the feasibility of their sampling and analysis methods through the construction of a project schedule and budget. Data validation and statistical interpretation methods are expected to be explored by students, with an emphasis on a comparison of contaminant concentrations with governmental regulations towards providing a final conclusion on the significance of the extent of contamination.

Communication skills are also emphasized through the consulting project. Students are expected to exhibit professionalism through deliverables and to relate technical aspects clearly and concisely to both technical and non-technical audiences in written and oral forms. Students are expected to present confidently, cohesively, and professionally, and to demonstrate strong argumentation and persuasion skills. Lastly, emphasis is placed on the appropriate and effective use of visual aids to clearly and concisely communicate information.

Dealing with ambiguity is another important competency which has proven more challenging to teach. While students are presented with the project structure and expectations, as well as some resources which guide them through their research, a model template for the deliverables is not provided. Students are expected to make appropriate interpretation of the instructions provided. The objective of this process is to teach students to conduct independent research and gain confidence in their judgement. The students are also expected to identify information they require so as to encourage active rather than passive learning.

In addition to meeting objectives within the Environmental Chemistry course, the consulting project is aligned with the degree requirement that students build a communications portfolio in order to graduate. This portfolio includes examples of communication assignments, both written and oral, taken from their undergraduate careers. Students also include reflections and summaries so as to promote ongoing improvement. To facilitate the incorporation of communications pieces, such as the formal client meeting presentation or final written proposal, into the communications portfolio, written reflections are incorporated into the Consulting Engineering project at specific points.

\subsection{Project Structure}

Figure 1 summarizes the progression of the project throughout the term. To achieve the primary objective of the project, which is to teach students about the consulting engineering process, the project is structured as realistically as possible, simulating how the project would typically proceed in government or industry.

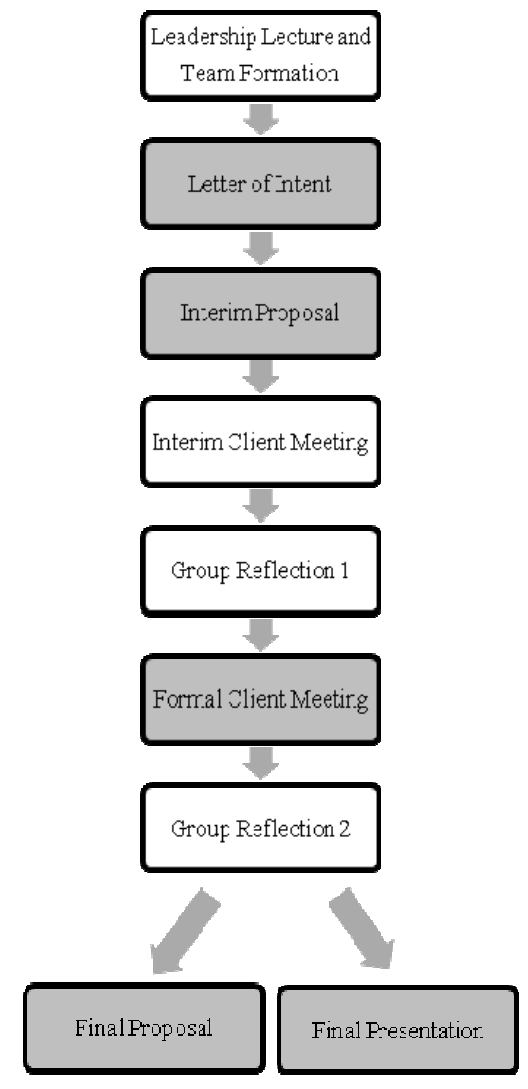

Figure 1. Project Process; highlighted in gray are project deliverables submitted for grading.

Embedded within the structure of the project are multiple opportunities for obtaining feedback from the instructors, which enable an iterative learning process. Following an initial request for proposals sent out by Wallberg Multicorp, the project progresses through a series of milestones, namely a letter of intent, preliminary proposal, interim client meeting, formal client meeting and final proposal. In total, the consulting project represents $15 \%$ of the student's final grade in the Environmental Chemistry course. 
The first component of the project involves team formation. Prior to forming teams, a lecture is given on effective teamwork. The lecture describes the importance of establishing a foundation of trust, constructive conflict and diverse perspectives [1]. A simple questionnaire is completed by the students so they can determine their preferred leadership styles [2]. With this new information in mind, students are advised to form teams which include members from all four leadership styles. This process allows for a student-based selection process while discouraging the tendency of students to seek out group members with similar styles to themselves.

Once presented with three different requests for proposals (RFP's) from Wallberg Multicorp, students must choose one scenario and compete for their choice through a letter of intent. Worth 5\% of the project grade, this one-page letter is designed to give students first contact with the professional context by asking them to state their project intentions, and to provide a preliminary indication of their project sampling and analysis methodology, in a professional letter. As part of this first task, they must also come up with a consulting company name and logo, a step where students get to exercise creative license. Groups with the weakest letters of intent risk being reassigned to a different scenario if reassignment is needed in order to have an even distribution of groups among all three scenarios.

This letter is followed by the submission of a preliminary proposal which is allotted $25 \%$ of the project grade. The preliminary proposal serves the function of a first draft. This stage in the project is inherently the most ambiguous, as it represents the students' first attempt at designing their proposal; students are required to identify the structure and contents of an environmental consulting proposal based on their review of relevant literature and prominent real-world consultancy websites. The proposal is expected to include a sampling and analysis strategy which is to be justified through engineering and economic considerations; claims are to be supported with appropriate graphics which should include a map of the sampling area and sampling plan, and may also include graphics explaining pertinent aspects of analytical measurement techniques. A budget and timeline are also expected. The preliminary proposal is graded using the same rubric as that for the final proposal, which considers the technical approach, communications and professionalism.

An interim client meeting is scheduled immediately following the preliminary proposal to allow students to obtain verbal feedback and provide them with the opportunity to ask questions regarding written feedback from the interim proposal. Feedback is also provided to guide students towards what is required to compose such a proposal, should they not have been fully successful in finding this information themselves. The first reflection for the communications portfolio is submitted following this meeting.

The next phase of the project involves the formal client meeting, which is worth $25 \%$ of the project grade. The students take this role-play very seriously, adopting formal conduct and attire. Students present their proposal to two "representatives" from Wallberg Multicorp: the president, who may or may not have technical knowledge regarding the methods proposed, and a senior vice-president, who has an engineering background outside of the environmental field. With this mixed technical and non-technical audience in mind, students are required to present their proposal to the representatives in 5-7 minutes. The only visual aid allowed is a four-page handout to be distributed to the representatives. The brevity of this handout is designed to push students towards summarizing their project effectively, using concise language and appropriate visuals. Representatives from Wallberg Multicorp role-play for both the presentation and a question and answer period, during which the representatives test the students' knowledge on various aspects of the project. This Q\&A period challenges students to deal with the representatives' unexpected questions and comments, a process which students will likely not have yet encountered in their undergraduate career. Following the question and answer period, the representatives revert to their instructor roles for the last few minutes of the meeting to provide constructive feedback. The best presentation from each scenario is selected to present to the entire class as well as a panel of judges (comprised of environmental consultants from industry); the winning groups are exempt from submitting the final proposal. The second reflection is submitted by all groups following the formal client meeting.

The final proposal, valued at $45 \%$ of the project grade, allows the students to integrate all that they have learned throughout the project and capture it in the final deliverable.

\subsection{Ongoing Feedback}

The iterative nature of the project allows students to improve throughout the duration of the project with the highest grade weighting applied to the final deliverable. A number of formal feedback points are designed into the project structure. Informal opportunities are also made available to students 
including e-mailing or meeting with the course instructors or Engineering Communication instructors as well as access to on-line tools [3] or discussions on the online course portal.

The first designated point of feedback is the interim proposal which is returned to the students with a detailed commentary on the strengths and weaknesses of the document. The students are given a few days to reflect on these comments prior to meeting with the course instructors at the interim client meeting.

During the interim client meeting students meet with the course instructor along with an instructor from the Engineering Communication Program to clarify any issues raised in the written feedback and determine where to focus their efforts to improve upon their document. Since the ability to defend their choice of sampling and chemical analysis strategies is examined throughout the project, the most common questions at this point of the project tend to revolve around how they should perform this task. Assistance is provided as needed to help the students understand the rationale that is to be applied to explain their choices.

The formal client meeting is also directly followed by an immediate feedback session. The feedback covers both the technical and communications aspects of the project. It also includes constructive criticism on each of the members' presentation skills (e.g. clarity and projection of voice, attention to other speakers, confidence level as well as the initial hand shake).

Another feedback point is the final presentation session for the winning groups. This experience is an integral teachable moment for both presenters and students in the audience. The panel of judges consisting of environmental consultants from industry help simulate the actual project delivery process. The presentation integrates all of the work done to date and provides an opportunity for the students in the audience to consider aspects of their selected scenario that they may not have addressed already. Following their presentations, the winning teams are questioned by the panel of judges as they were in the formal client meetings; however this process differs significantly from the previous one as the students have never met the judges. This question and answer period is valuable as it incorporates the judges' real-world experience in the field. The rest of the class observes the presentations and the judges' comments, using it as an opportunity to improve their own proposals. The class is also allowed to ask questions during the presentations. The presentation session typically ends with some brief comments from each consultant and a question and answer session so that the class can learn from the panel's experience in the environmental consulting field.

\section{Project Impact}

The impact of the project with regards to the learning objectives is evaluated through the course deliverables, two group reflections completed as a mandatory hand-in assignment, as well as through course evaluations. The deliverables allow direct evaluation of the teams' technical and communication abilities along with their progress over the term. The reflections evaluate the project experience from a student's perspective. The final course evaluation considers the overall effectiveness of the consulting project.

\subsection{Team Reflections}

The teams are presented with a set of questions to guide them though a structured reflection on their team process. The teams examine their overall performance while identifying team weaknesses and steps for improvement. These reflections provide insight into the students' perspective on their technical and communication abilities, and how they are coping with the ambiguity of the project. The reflections also help identify teams that may require immediate or long-term intervention.

The following section summarizes reflections obtained from the most recent academic session. A summary of the teams' perceived strengths and weaknesses is provided in Table 1.

Table1. Perceived team strengths and weaknesses identified through the 22 team reflections from 2010

\begin{tabular}{|l|c|c|}
\hline & Strength & Weakness \\
\hline Professionalism & $30 \%$ & $17 \%$ \\
\hline Organisation & $30 \%$ & $4 \%$ \\
\hline Visual Aids & $12 \%$ & $38 \%$ \\
\hline Conveying Message & $0 \%$ & $8 \%$ \\
\hline Technical Content & $28 \%$ & $33 \%$ \\
\hline
\end{tabular}

\subsubsection{Team Dynamics}

In the first reflection, most teams identified teamwork as an important element for success in this project. However, they found that their work-load competed with having face-to-face team meetings. These meetings were often replaced by communication over e-mail and telephone, which they commented on as being ineffective as it resulted in divergent comprehension of the team objectives and expectations. This, in turn, sometimes manifested in 
group conflicts or inconsistencies in communications and technical approach throughout the creation of the interim proposal.

In the second reflection, meeting scheduling remained a challenge for almost all groups. This problem was compounded by the stress surrounding the midterm season. Some groups overcame the challenge and managed to turn into functional teams, as evidenced by a listing of "creativity, mutual accountability and responsibility" as important elements for success of the project. On the other hand, some teams did not develop into an effective team and continued to approach the project as a group of individuals. These groups continued to rank fair division of work among members as one of the most important elements for the overall success of the project and failed to achieve mutual accountability throughout the team.

Out of the 22 teams, only three reported a major conflict over the two reflections. These groups listed time-management, lack of interest and poor communication between members as causes of their conflict.

Both reflections asked students whether or not they were having fun. An overwhelming majority of the 22 teams agreed that they were enjoying the project. The number of groups who stated they were having fun increased from 18 in the first reflection to 20 in the second reflection. Many teams stated that they were having more fun after the formal client meeting than at the previous point in the term, and indicated that they enjoyed this interactive and challenging aspect of the project, calling it the most interesting part of the project.

\subsubsection{Technical Skills}

In the first reflection, most groups stated that they were unable to justify their choice of sample location and testing methodology in the body of the document. These responses provided an indication that this project afforded students a unique learning opportunity to learn how to justify their engineering judgements with sound research. However, it also indicated that students were having some difficulty in navigating the open-endedness and ambiguity of the early phases of the project. Finding credible sources was cited as a significant challenge, particularly given that in the first instance students relied heavily on using the internet for conducting their research.

In the second reflection, most students indicated that they comprehended the need for providing a rationale to support their engineering judgements however they also claimed that they were still having some difficulty with this task. When teams were asked to name the most interesting thing they have learned about engineering consulting through the project, five teams identified the acquisition of budget formation skills as the most valuable.

\subsubsection{Communication}

Detailed but concise writing was a major challenge for students in the interim proposal. In the first reflection, students said that they were unable to identify the appropriate level of detail to provide, which indicated they were struggling with ambiguity. Students also had trouble constraining the formal client meeting presentation to 5-7 minutes. Students also claimed to be unsure about which aspects of the proposal to focus on.

Communication through visuals was a major challenge throughout the project. A sampling map and a timeline (often presented in a Gantt chart) was a requirement for the interim proposal. Ten out of the 22 teams claimed that they had failed to provide visuals in the body of the document, and relegated them to the appendices to meet the page limit. In the second reflection, nine teams identified visuals as the weakest aspect of their client meeting while only three groups believed that visual aids were their strongest element.

By contrast, most groups found that their strengths lay in their ability to professionally communicate with the client. Highlighted particularly in the client meeting, students were able to properly introduce themselves and the project, show confidence and dress professionally. In the second reflection, $30 \%$ of the teams named "professionalism" as their main strength while only $17 \%$ felt that it was their greatest weakness.

When teams were asked to name one of the most interesting things they have learned about engineering consulting through the project, five teams emphasized their newly discovered understanding of the importance of communication skills in engineering.

\subsection{Course Evaluations}

In addition to the group reflections, students in 2010 were asked at the end of the course to anonymously, and individually, respond to a series of targeted questions with respect to the consulting project. The student responses used a seven-point Likert scale, where 1 represented inadequate and 7 represented outstanding. Overall, there was a relatively positive response with respect to the perceived value of the consulting project experience: the average of 4.8 which was comparable to the Faculty average of 4.7 for student learning experience. Similar response rates were given for the perceived value for the project's 
role in improving one's communications skills (4.6) and learning the technical aspects of environmental assessment (4.7). Admittedly, these scores indicated room for improvement.

Long-form feedback on suggestions to improve the course was also solicited. While several important points were raised, the most important one comprised expectations at the onset of the project. Whereas one of the project objectives entailed having students learn to deal with ambiguity in the form of researching the content and structure of an environmental consulting proposal, this posed a conflict in learning outcomes and objectives: a significant number of students mentioned that this expectation was unrealistic and necessitated too much work on their part.

\subsection{Course Deliverables}

Learning was assessed through a comparison of the interim proposal and final deliverable in terms of the six project components (Table 2). A grade of $75 \%$ indicated that a team had achieved the desired level of learning; $68 \%$ of the teams achieved this criterion in all the components. Further, the class improved on average in all the components.

Table 2. Assessment of learning of the six project components through the course deliverables

\begin{tabular}{|l|c|c|}
\hline \multicolumn{1}{|c|}{ Project Component } & $\begin{array}{c}\text { Interim } \\
\text { Proposal }\end{array}$ & $\begin{array}{c}\text { Final } \\
\text { Deliverable }\end{array}$ \\
\hline Problem Contextualization & $68 \%$ & $82 \%$ \\
\hline Sampling Method & $68 \%$ & $91 \%$ \\
\hline Sample Analysis Method & $55 \%$ & $86 \%$ \\
\hline Data Interpretation & $64 \%$ & $91 \%$ \\
\hline Timeline \& Budget & $36 \%$ & $86 \%$ \\
\hline Presentation & $55 \%$ & $95 \%$ \\
\hline
\end{tabular}

The largest improvement was in the area of constructing a project timeline and budget. This component was also identified in many of the team reflections as the most interesting thing learned from the project. Furthermore, students demonstrated through their final deliverable that they learned how to rationalize their engineering judgements in terms of their sampling and chemical analysis methods.

\section{Conclusions}

The Consulting Engineering project provides a valuable learning experience to second year chemical engineering students. Students learn how to effectively communicate technical material to both technical and non-technical audiences. Students also learn how to approach the assessment of an environmental problem in the context of consulting engineering. Learning objectives relating to the development of key engineering competencies such as communication, technical skills and professionalism are tested and developed through an iterative learning process.

The incorporation of two guided reflections throughout the course improves learning by both the students and the instructors. These reflections facilitate the use of key pieces of the project such as the formal client meeting and final proposal as submissions for the communications portfolio. The reflections also allow for more explicit interactions and cross-learning between courses, which has the added benefit of students being able to see how their curriculum fits together as a whole. These reflections will thus likely be kept for future years.

The team-based leadership lecture at the beginning of the project provides an opportunity to mitigate some of the conflicts that arise among many teams during the term. In future years, this lecture will be expanded to address the importance of having inperson meetings, setting group guidelines and managing expectations.

Overall, the project is well received by many, but not all, students. Some students voiced concerns about the work load and are frustrated by the project's ambiguity. This expectation is being given careful consideration for future delivery of the project, and may be revised so as to provide more guidance at the onset of the project. In contrast, many students state that they find the project to be both a valuable and fun learning experience.

\section{Acknowledgements}

The authors would like to acknowledge the contributions Parnian Jadidian and Abla Eldib, two former CHE230 students, who helped draft this manuscript. The past contributions of Chris Ambidge and Penny Seymour during the formative stages of the project are also acknowledged.

\section{References}

[1] Zafft, C.R., S.G. Adams and G.S. Matkin (2009) "Measuring leadership in Self-Managed Teams Using the Competing Values Framework. J. Engineering Education 98, 3 273-282

[2] Bolton, Robert, Grover-Bolton Dorothy, People Styles at Work: Making Bad Relationships Good and Good Relationships Better Amacon, New York, 1996.

[3] Engineering Communication Program, University of Toronto. Engineering Document Handbook, Online, 2008. http://www.engineering.utoronto.ca/Directory/Student_Reso urces/Engineering_Communication_Program/Online_Handb ook.htm 